\title{
Acylation of aromatic ethers over solid acid catalysts: scope of the reaction with more complex acylating agents
}

\author{
Keith Smith, ${ }^{* a}$ Gamal A. El-Hiti, $\uparrow^{a}{ }^{a}$ Anthony J. Jayne ${ }^{a}$ and Michael Butters ${ }^{b}$ \\ ${ }^{a}$ Centre for Clean Chemistry, Department of Chemistry, University of Wales Swansea, \\ Singleton Park, Swansea, UK SA2 8PP \\ ${ }^{b}$ AstraZeneca, Global Process R\&D, Avlon Works, Bristol, UK BS10 7ZE
}

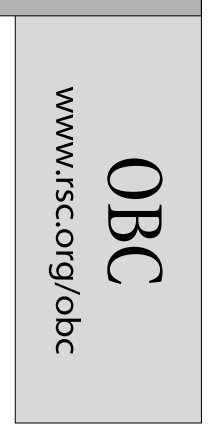

Received 10th April 2003, Accepted 13th May 2003

First published as an Advance Article on the web 28th May 2003

Acylation of anisole with 2-phenylbutanoic acid derivatives, over zeolite catalysts, gives the corresponding 4-acyl derivatives with high regioselectivity. In an analogous way, 2,3-dihydrobenzofuran reacts with acid anhydrides or chlorides in the presence of catalytic quantities of zeolites to give the corresponding 5-acyl-2,3-dihydrobenzofurans. The zeolite can be recovered, regenerated and used again to give almost the same yield as with fresh zeolite. The reaction has been applied to the synthesis of ethyl (2,3-dihydrobenzofuran-5-yl)glyoxylate.

\section{Introduction}

Friedel-Crafts acylation reactions are among the most important for synthesis of aromatic ketones. ${ }^{1}$ In order to allow the reaction to proceed at satisfactory rates, activators such as Lewis acids or other co-catalysts are usually needed. Unfortunately, use of such activators involves a number of problems. For example, the activators may be needed in more than stoichiometric amounts. Work-up usually leads to loss of activator and generation of large quantities of corrosive and toxic wastes. Moreover, reactions are often not clean and lead to the production of mixtures of products with low selectivity.

The use of recoverable and regenerable solid catalysts such as zeolites can overcome many problems of these types. For example, we have shown that zeolites or other solids can have advantages in alkylation, ${ }^{2}$ allylation, ${ }^{3}$ bromination, ${ }^{3,4}$ chlorination, ${ }^{6,7}$ methanesulfonylation ${ }^{8}$ and nitration ${ }^{9-14}$ of aromatic compounds. Therefore, the development of new heterogeneous catalytic procedures for acylation of organic compounds has become a priority for the chemical industry, ${ }^{15,16}$ and acylation of aromatic compounds over zeolites has been the subject of a number of reports. ${ }^{17}$ Indeed, such a process has been commercialised. ${ }^{18}$

We have also shown that it is possible to achieve high yield acylation of aromatic ethers with acetic anhydride and other simple anhydrides under modest conditions over zeolite $\mathrm{H} \beta{ }^{19,20}$ For some potential applications in the fine chemicals/ pharmaceuticals area, however, the reactions would need to involve more complex ethers and/or more complex acylating agents, not necessarily available in anhydride form. In this paper we report on the regioselective acylation of anisole and 2,3-dihydrobenzofuran over zeolites with more complex acylating agents.

\section{Results and discussion}

Recently, we showed that anisole is acetylated with acetic anhydride over zeolite $\mathrm{H} \beta$ to give 4-methoxyacetophenone in $98 \%$ yield after $2 \mathrm{~h}$ at $120^{\circ} \mathrm{C} \cdot{ }^{19} 1$-(4-Methoxyphenyl)-2-phenyl1-butanone (2) is a useful pharmaceutical intermediate and is usually produced under Friedel-Crafts conditions using $\mathrm{AlCl}_{3}$ as activator. Our aim was to develop a more environmentally benign route to this intermediate utilising solids as catalysts. We now report success in this endeavour. The 2-phenylbutanoylation of anisole (1) with various acyl derivatives over a large

$\dagger$ Permanent address: Department of Chemistry, Faculty of Science, Tanta University, Tanta 31527, Egypt.
Table 1 Synthesis of $\mathbf{2}$ over different catalysts using various acylating agents according to equation $(1)^{a}$

\begin{tabular}{llrll}
\hline Catalyst $^{b}$ & $\mathrm{X}$ & $t / \mathrm{h}$ & $T /{ }^{\circ} \mathrm{C}$ & Yield (\%) $^{c}$ \\
\hline $\mathrm{H} \beta$ & $\mathrm{Cl}$ & 5 & 85 & 43 \\
$\mathrm{~K} 10$ & $\mathrm{Cl}$ & 5 & 85 & 66 \\
$\mathrm{HY}$ & $\mathrm{Cl}$ & 5 & 85 & 40 \\
$\mathrm{H} \beta$ & $\mathrm{CF}_{3} \mathrm{CO}_{2}$ & 4 & Reflux & 96 \\
$\mathrm{~K} 10$ & $\mathrm{CF}_{3} \mathrm{CO}_{2}$ & 4 & Reflux & 78 \\
$\mathrm{H} \beta$ & $\mathrm{OH}$ & 24 & 85 & - \\
$\mathrm{K} 10$ & $\mathrm{OH}$ & 24 & 85 & - \\
$\mathrm{H} \beta$ & $\mathrm{EtCH}(\mathrm{Ph}) \mathrm{CO}_{2}{ }^{d}{ }^{d}$ & 4 & 120 & 48 \\
$\mathrm{~K} 10$ & $\mathrm{EtCH}(\mathrm{Ph}) \mathrm{CO}_{2}{ }^{2}$ & 4 & 120 & 86
\end{tabular}

${ }^{a}$ A mixture of freshly calcined catalyst $(0.50 \mathrm{~g})$, acylating agent $(12.0 \mathrm{mmol})$ and anisole $(1.08 \mathrm{~g}, 10.0 \mathrm{mmol})$ was heated for the stated reaction time. ${ }^{b}$ Zeolite $\mathrm{H} \beta$ was calcined at $400{ }^{\circ} \mathrm{C}$ and $\mathrm{K} 10$ at $110{ }^{\circ} \mathrm{C}$ prior to use. ${ }^{c}$ Yields for isolated, purified materials. ${ }^{d}$ Acylating agent (20 mmol) was used.

pore zeolite $(\mathrm{H} \beta)$ and a clay (K10, an acid-treated montmorillonite) afforded 2 (eqn. (1)) in good yields (Table 1).<smiles>[X]C(=O)C([X])c1ccccc1</smiles>

It is clear from the results recorded in Table 1 that 2-phenylbutanoyl trifluoroacetate, formed in situ from 2-phenylbutanoic acid and trifluoroacetic anhydride, was the most effective reagent, giving a $96 \%$ yield of 2 after 4 h at reflux over $\mathrm{H} \beta$ in dichloromethane as solvent. A lower degree of acylation occurred with 2-phenylbutanoyl chloride, giving a $43 \%$ yield after $5 \mathrm{~h}$ at $85^{\circ} \mathrm{C}$ over $\mathrm{H} \beta$, while hardly any reaction occurred with 2-phenylbutanoic acid. From Table 1, it appears that the order of the reactivity of acylating agents used is: mixed anhydride with trifluoroacetic anhydride $>$ simple anhydride, acid chloride $>$ carboxylic acid.

Samples of zeolite HY and clay K10 that were recovered from reactions depicted in eqn. (1) were regenerated by calcination at 400 and $110{ }^{\circ} \mathrm{C}$, respectively and reused in reactions that were identical to the ones from which the samples were recovered. In all cases the yields were virtually the same. 
Table 2 Synthesis of 5-acyl-2,3-dihydrobenzofurans (4) according to equation (2) ${ }^{a}$

\begin{tabular}{|c|c|c|c|c|}
\hline Product & Catalyst $^{b}$ & $\mathrm{R}$ & $t / \mathrm{h}$ & Yield $(\%)^{c}$ \\
\hline $4 a$ & $\mathrm{H} \beta$ & Et & 1.5 & 90 \\
\hline $4 b$ & $\mathrm{H} \beta$ & $\operatorname{Pr}^{i}$ & 1.5 & 70 \\
\hline $4 c$ & $\mathrm{H} \beta$ & $\mathrm{Bu}^{t}$ & 1.5 & 18 \\
\hline $4 c$ & $\mathrm{H} \beta$ & $\mathrm{Bu}^{t}$ & 4.5 & 29 \\
\hline $4 c$ & $\mathrm{HY}$ & $\mathrm{Bu}^{t}$ & 4.5 & 57 \\
\hline $4 c$ & K10 & $\mathrm{Bu}^{t}$ & 5.0 & 23 \\
\hline $4 c$ & $\mathrm{KSF}$ & $\mathrm{Bu}^{t}$ & 5.0 & 6 \\
\hline $4 c$ & Synclyst 13 & $\mathrm{Bu}^{t}$ & 5.0 & 2 \\
\hline $4 c$ & Synclyst 25 & $\mathrm{Bu}^{t}$ & 5.0 & 2 \\
\hline 4d & $\mathrm{H} \beta$ & $\mathrm{Ph}$ & 1.5 & 26 \\
\hline 4d & $\mathrm{H} \beta$ & $\mathrm{Ph}$ & 4.5 & 29 \\
\hline 4d & $\mathrm{HY}$ & $\mathrm{Ph}$ & 4.5 & 40 \\
\hline $4 d$ & K10 & $\mathrm{Ph}$ & 5.0 & 73 \\
\hline $4 d$ & KSF & $\mathrm{Ph}$ & 5.0 & 29 \\
\hline 4d & Synclyst 13 & $\mathrm{Ph}$ & 5.0 & 27 \\
\hline 4d & Synclyst 25 & $\mathrm{Ph}$ & 5.0 & 35 \\
\hline $4 e$ & $\mathrm{H} \beta$ & $\mathrm{CH}_{2} \mathrm{Cl}$ & 1.5 & 8 \\
\hline $4 f$ & $\mathrm{H} \beta$ & $\mathrm{CF}_{3}$ & 4.5 & 0 \\
\hline $4 \mathrm{~g}$ & $\mathrm{H} \beta$ & $\mathrm{CCl}_{3}$ & 4.5 & 0 \\
\hline
\end{tabular}

${ }^{a}$ A mixture of freshly calcined catalyst $(0.5 \mathrm{~g}),(\mathrm{RCO})_{2} \mathrm{O}(20.0 \mathrm{mmol})$ and $3(1.2 \mathrm{~g}, 10.0 \mathrm{mmol})$ was stirred at $120^{\circ} \mathrm{C}$ for the stated reaction time. ${ }^{b}$ Zeolites and synclyst were calcined at $400{ }^{\circ} \mathrm{C}$ and clays at $110^{\circ} \mathrm{C}$ prior to use. ${ }^{c}$ Reaction mixtures were purified by short path distillation or flash column chromatography and solids were crystallised from appropriate solvents.

We were also interested to study the reactions with more complex substrates, in particular 2,3-dihydrobenzofuran. We have already shown that acetylation of 2,3-dihydrobenzofuran (3) using acetic anhydride over $\mathrm{H} \beta(0.5 \mathrm{~g}$ per $10 \mathrm{mmol}$ of 3$)$ at $120{ }^{\circ} \mathrm{C}$ for $1.5 \mathrm{~h}$ gave 5-acetyl-2,3-dihydrobenzofuran in $95 \%$ yield. ${ }^{20}$ Therefore, we first examined various more complex anhydrides for the regioselective acylation of $\mathbf{3}$ over various types of solid catalysts in the absence of solvent (eqn. (2)). The results obtained are given in Table 2 .

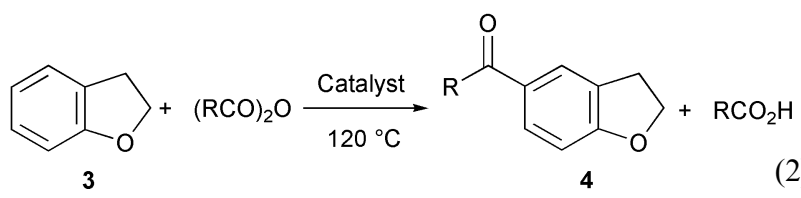

It was clear from the results that $\mathrm{H} \beta$ is not as effective as a catalyst for reactions involving more hindered anhydrides $(90 \%$ yield after $1.5 \mathrm{~h}$ when $\mathrm{R}=\mathrm{Et}$, compared to $29 \%$ after $4.5 \mathrm{~h}$ when $\mathrm{R}=\mathrm{Ph}$ or $\left.\mathrm{Bu}^{t}\right)$. However, $\mathrm{HY}$ showed a modest improvement (40 and $57 \%$, respectively for $\mathrm{R}=\mathrm{Ph}$ and $\mathrm{Bu}^{t}$ after $4.5 \mathrm{~h}$ ). In some cases a better yield was achieved over K10 (73\% yield after $5 \mathrm{~h}$ when $\mathrm{R}=\mathrm{Ph}$ ), while with the more hindered anhydride $\left(\mathrm{R}=\mathrm{Bu}^{t}\right), \mathrm{K} 10$ gave a lower yield than $\mathrm{H} \beta$. A very low degree of acylation occurred with trimethylacetic anhydride over synclyst (an amorphous silica-alumina) under the same conditions, and trifluoroacetic and trichloroacetic anhydrides did not react at all over zeolite $\mathrm{H} \beta$ under mild conditions. The order of activity of various catalysts in the reaction of 3 with the hindered anhydrides appeared to be $\mathrm{HY}>\mathrm{H} \beta>\mathrm{K} 10>$ synclyst. Clearly, both $\mathrm{HY}$ and $\mathrm{H} \beta$ catalyse reactions reasonably effectively, but $\mathrm{K} 10$ is more variable in its effect. Both $\mathrm{HY}$ and $\mathrm{H} \beta$ zeolites have 12-T ring apertures, but the faujasite zeolite $(\mathrm{Y})$ has an aperture diameter of $7.4 \AA$, whereas zeolite $\beta$ has pore diameters of $7.0 \times$ $6.4 \AA$ and $5.5 \times 5.5 \AA$, respectively. Therefore, the adsorption of both benzoic and trimethylacetic anhydrides into the pores of zeolite $H \beta$ is restricted, which may be the cause of the lower yields of product.

Samples of zeolites HY and $\mathrm{H} \beta$ that were recovered from the reaction depicted in eqn. (2) were regenerated by calcination at $400{ }^{\circ} \mathrm{C}$ and reused in reactions that were identical to the ones
Table 3 Effect of temperature and time on the synthesis of 5 over $\mathrm{H} \beta$ according to equation (4) ${ }^{a}$

\begin{tabular}{rrlr}
\hline & & \multicolumn{2}{l}{ Yield $(\%)^{b}$} \\
\cline { 3 - 4 }$t / \mathrm{h}$ & $T /{ }^{\circ} \mathrm{C}$ & $\mathbf{3}$ & $\mathbf{5}$ \\
& & & \\
\hline 1 & 18 & 99 & 0 \\
24 & 18 & 99 & 0 \\
1 & 50 & 95 & 1 \\
24 & 50 & 92 & 7 \\
1 & 100 & 86 & 9 \\
24 & 100 & 81 & 10
\end{tabular}

${ }^{a}$ A mixture of freshly calcined $\mathrm{H} \beta(0.50 \mathrm{~g})$, ethyl oxalyl chloride $(1.64 \mathrm{~g}$, $12.0 \mathrm{mmol})$, DHBF $(1.20 \mathrm{~g}, 10.0 \mathrm{mmol})$ and hexadecane $(0.70 \mathrm{~g}, \mathrm{GC}$ standard) was stirred at the indicated temperature for the stated reaction time. ${ }^{b}$ Determined by quantitative GC analysis.

from which the samples were recovered. In all cases the yields were virtually the same.

Attention was next turned to the acylation of $\mathbf{3}$ using ethyl oxalyl chloride as acylating agent to produce ethyl (2,3-dihydrobenzofuran-5-yl)glyoxylate (5), which is an useful pharmaceutical intermediate. The Friedel-Crafts acylation of $\mathbf{3}$ with ethyl oxalyl chloride in the presence of $\mathrm{AlCl}_{3}$, which is a typical process such as might be used commercially, gave the desired product $\mathbf{5}$ in $88 \%$ yield (eqn. (3)).

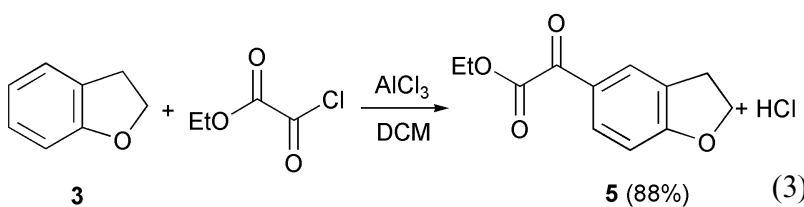

The aim of this work was, therefore, to develop a more attractive alternative to traditional Friedel-Crafts acylation methodologies, by using heterogeneous catalysts to promote the acylation of $\mathbf{3}$ using ethyl oxalyl chloride. Initially, a range of solids, which included large pore zeolites (HY, HX, H $\beta$, $\mathrm{H}$-mordenite); a medium pore zeolite (HZSM-5); an amorphous synclyst; K10 and KSF clays; and a sulfonated cross-linked polystyrene resin (Amberlyst-15), was screened. It was noticed that no reaction took place at room temperature with any of these catalysts, only unreacted 3 being detected by GC. Therefore, a further series of experiments was conducted at higher temperatures $\left(50-100{ }^{\circ} \mathrm{C}\right)$ using the same catalysts. A trace amount of the desired product $\mathbf{5}(<0.3 \%)$ was detected from the reactions catalysed by $\mathrm{HY}$ and synclyst at $50{ }^{\circ} \mathrm{C}$, while the use of $\mathrm{H} \beta$ (eqn. (4)) gave the desired product 5 in $1-10 \%$ yield (Table 3).

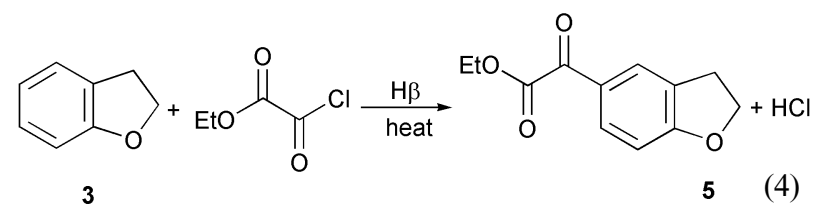

Although the yield of $\mathbf{5}$ achieved at elevated temperatures was still very low, the results showed that the yield increased with reaction temperature. It therefore seemed reasonable to investigate the variation of other reaction parameters, and the effect of solvent at different reaction times and temperatures over $\mathrm{H} \beta$ was next studied. The results obtained are given in Table 4.

The results in Table 4 reveal that the yield of 5 can be increased to $c a$. $20 \%$ when reactions are carried out in chlorinated solvents under reflux conditions for prolonged periods, but this is still far from satisfactory. Since a greater quantity of zeolite catalyst should cause the reaction to proceed at a faster rate, a series of reactions in which the amount of zeolite $\mathrm{H} \beta$ was increased was next conducted. The results are shown in Table 5. 
Table 4 Effect of solvent on the synthesis of 5 over $\mathrm{H} \beta$ according to equation (4) ${ }^{a}$

\begin{tabular}{|c|c|c|c|c|}
\hline \multirow[b]{2}{*}{ Solvent } & \multirow[b]{2}{*}{$t / \mathrm{h}$} & \multirow[b]{2}{*}{$T /{ }^{\circ} \mathrm{C}$} & \multicolumn{2}{|c|}{ Yield $(\%)^{b}$} \\
\hline & & & 3 & 5 \\
\hline $\mathrm{CH}_{2} \mathrm{Cl}_{2}$ & 24 & 40 & 87 & 10 \\
\hline $\mathrm{CH}_{2} \mathrm{Cl}_{2}$ & 48 & Reflux & 78 & 14 \\
\hline $\mathrm{CH}_{2} \mathrm{Cl}_{2}$ & 72 & Reflux & 72 & 19 \\
\hline $\mathrm{PhCl}$ & 24 & 50 & 82 & 7 \\
\hline $\mathrm{PhCl}$ & 24 & 132 & 72 & 15 \\
\hline $\mathrm{PhCl}$ & 48 & Reflux & 66 & 13 \\
\hline $\mathrm{PhCl}$ & 72 & Reflux & 67 & 14 \\
\hline $\mathrm{CHCl}_{3}$ & 24 & 50 & 88 & 7 \\
\hline $\mathrm{CHCl}_{3}$ & 24 & 62 & 85 & 12 \\
\hline $\mathrm{CHCl}_{3}$ & 48 & Reflux & 72 & 20 \\
\hline $\mathrm{CHCl}_{3}$ & 72 & Reflux & 74 & 20 \\
\hline $\mathrm{ClCH}_{2} \mathrm{CH}_{2} \mathrm{Cl}$ & 24 & 50 & 87 & 8 \\
\hline $\mathrm{ClCH}_{2} \mathrm{CH}_{2} \mathrm{Cl}$ & 24 & 83 & 74 & 17 \\
\hline $\mathrm{ClCH}_{2} \mathrm{CH}_{2} \mathrm{Cl}$ & 48 & Reflux & 75 & 20 \\
\hline $\mathrm{ClCH}_{2} \mathrm{CH}_{2} \mathrm{Cl}$ & 72 & Reflux & 72 & 20 \\
\hline $\mathrm{CH}_{3} \mathrm{COCH}_{3}$ & 24 & 50 & 89 & $<1$ \\
\hline $\mathrm{CH}_{3} \mathrm{COCH}_{3}$ & 24 & 56 & 89 & $<1$ \\
\hline $\mathrm{CH}_{3} \mathrm{CN}$ & 24 & 50 & 99 & $<1$ \\
\hline $\mathrm{CH}_{3} \mathrm{CN}$ & 24 & 82 & 99 & $<1$ \\
\hline
\end{tabular}

${ }^{a}$ A mixture of freshly calcined $\mathrm{H} \beta(0.50 \mathrm{~g})$, ethyl oxalyl chloride (1.64 g, $12.0 \mathrm{mmol}), \mathrm{DHBF}(1.20 \mathrm{~g}, 10.0 \mathrm{mmol})$, solvent $(5.0 \mathrm{ml})$ and hexadecane $(0.70 \mathrm{~g}, \mathrm{GC}$ standard $)$ was stirred at the indicated temperature for the stated reaction time. ${ }^{b}$ Determined by quantitative GC analysis.

Table 5 Effect of quantity of $\mathrm{H} \beta$ catalyst on the synthesis of $\mathbf{5}$, according to equation (4), ${ }^{a}$ in chlorinated solvents

\begin{tabular}{llll}
\hline & & \multicolumn{2}{l}{ Yield $(\%)^{b}$} \\
\cline { 3 - 4 } Quantity of $\mathrm{H} \beta / \mathrm{g}$ & Solvent & $\mathbf{3}$ & $\mathbf{5}$ \\
\hline 1 & $\mathrm{CH}_{2} \mathrm{Cl}_{2}$ & 74 & 21 \\
2 & $\mathrm{CH}_{2} \mathrm{Cl}_{2}$ & 64 & 26 \\
1 & $\mathrm{CHCl}_{3}$ & 65 & 29 \\
2 & $\mathrm{CHCl}_{3}$ & 40 & 38 \\
1 & $\mathrm{ClCH}_{2} \mathrm{CH}_{2} \mathrm{Cl}$ & 60 & 29 \\
2 & $\mathrm{ClCH}_{2} \mathrm{CH}_{2} \mathrm{Cl}$ & 44 & 30
\end{tabular}

${ }^{a}$ A mixture of freshly calcined $\mathrm{H} \beta$, ethyl oxalyl chloride (1.64 g, 12.0 $\mathrm{mmol})$, DHBF $(1.20 \mathrm{~g}, 10.0 \mathrm{mmol})$, solvent $(5.0 \mathrm{ml})$ and hexadecane $\left(0.70 \mathrm{~g}, \mathrm{GC}\right.$ standard) was heated under reflux for $72 \mathrm{~h} .{ }^{b}$ Determined by quantitative $\mathrm{GC}$ analysis.

From the results in Table 5, it is clear that the yield of $\mathbf{5}$ was greater when a greater amount of $\mathrm{H} \beta$ was used. This can be ascribed to the increase in number of acid sites and pore cavities available. However, on the assumption that the rate of reaction should depend linearly on the amount of catalyst, it would appear that the extent of reaction did not increase as rapidly as might have been expected with the increased amount of catalyst. The reasons for this were not obvious at this stage, though it was noted that the recorded mass balances (the sum of the yields of product $\mathbf{5}$ and recovered starting material 3 ) were quite low with the larger quantities of zeolite.

In order to observe the effect of the amount of acylating agent on the reaction, a series of reactions was conducted using an excess amount of ethyl oxalyl chloride $(20.0 \mathrm{mmol})$ in different amounts of solvents and over various reaction times. The results are shown in Table 6.

A slightly better yield ( $51 \%$ ) was achieved by carrying out the reaction under reflux conditions for $168 \mathrm{~h}$ in chloroform $(10 \mathrm{ml})$ over $\mathrm{H} \beta(2.0 \mathrm{~g})$. The results showed that by carrying out the reaction in a high boiling solvent (chlorobenzene) for a prolonged period of time, in addition to the lowest yield being obtained, a considerable decrease in the total mass balance was observed. This is in agreement with the results tabulated in Table 4.
Table 6 Synthesis of 5 over H $\beta$, according to equation (4), ${ }^{a}$ in the presence of various amounts of chlorinated solvents

\begin{tabular}{|c|c|c|c|c|}
\hline \multirow[b]{2}{*}{ Solvent } & \multirow[b]{2}{*}{ Amount of solvent } & \multirow[b]{2}{*}{$t / \mathrm{h}$} & \multicolumn{2}{|c|}{ Yield $(\%)^{b}$} \\
\hline & & & 3 & 5 \\
\hline $\mathrm{CH}_{2} \mathrm{Cl}_{2}$ & 5 & 72 & 72 & 19 \\
\hline $\mathrm{CH}_{2} \mathrm{Cl}_{2}$ & 10 & 72 & 67 & 28 \\
\hline $\mathrm{CH}_{2} \mathrm{Cl}_{2}$ & 10 & 168 & 67 & 30 \\
\hline $\mathrm{CHCl}_{3}$ & 5 & 72 & 71 & 25 \\
\hline $\mathrm{CHCl}_{3}$ & 10 & 72 & 45 & 44 \\
\hline $\mathrm{CHCl}_{3}$ & 10 & 168 & 32 & 51 \\
\hline $\mathrm{ClCH}_{2} \mathrm{CH}_{2} \mathrm{Cl}$ & 5 & 72 & 73 & 23 \\
\hline $\mathrm{ClCH}_{2} \mathrm{CH}_{2} \mathrm{Cl}$ & 10 & 72 & 43 & 32 \\
\hline $\mathrm{ClCH}_{2} \mathrm{CH}_{2} \mathrm{Cl}$ & 10 & 168 & 31 & 39 \\
\hline $\mathrm{PhCl}$ & 10 & 168 & 23 & 29 \\
\hline
\end{tabular}

${ }^{a}$ A mixture of freshly calcined $\mathrm{H} \beta$ (2.00 g), ethyl oxalyl chloride (2.73 g, $20.0 \mathrm{mmol})$, DHBF $(1.20 \mathrm{~g}, 10.0 \mathrm{mmol})$, solvent $(5.0$ or $10.0 \mathrm{ml})$ and hexadecane $(0.70 \mathrm{~g}$, GC standard $)$ was heated under reflux for the stated reaction time. ${ }^{b}$ Determined by quantitative $\mathrm{GC}$ analysis.

Table 7 Synthesis of $\mathbf{5}$, according to equation (4), ${ }^{a}$ over various type of catalysts in $\mathrm{CHCl}_{3}$

\begin{tabular}{llr} 
& \multicolumn{2}{c}{${\text { Yield }(\%)^{b}}^{n}$} \\
\cline { 2 - 3 } Catalyst & $\mathbf{3}$ & $\mathbf{5}$ \\
\hline H $\beta$ & 32 & 51 \\
HY & 69 & 7 \\
H-Mordenite & 96 & 4 \\
HZSM-5 & 93 & 7 \\
HL & 99 & 1 \\
Synclyst 25 & 87 & 6 \\
K10 & 89 & 1 \\
ENVIROCAT EPZG & 84 & 1
\end{tabular}

${ }^{a}$ A mixture of freshly calcined $\mathrm{H} \beta$ (2.00 g), ethyl oxalyl chloride (2.73 g, $20.0 \mathrm{mmol})$, DHBF $(1.20 \mathrm{~g}, 10.0 \mathrm{mmol}), \mathrm{CHCl}_{3}(10.0 \mathrm{ml})$ and hexadecane $(0.70 \mathrm{~g}$, GC standard) was stirred under reflux for 7 days. ${ }^{b}$ Determined by quantitative GC analysis.

Although $\mathrm{H} \beta$ had proved to be the most effective catalyst at low temperatures, it was not clear that this would be true at the more elevated temperatures currently being used. Therefore, the effect of catalyst type on yield was investigated using various types of solid catalysts in refluxing chloroform. The results are shown in Table 7. From the results it is clear that none of the other catalysts give results comparable with those of $\mathrm{H} \beta$.

Detailed study of the results recorded in Table 7 revealed very low mass balance figures calculated by GC analysis of certain reactions. For example, a total mass balance of $76 \%$ was obtained when a reaction was catalysed by HY (Table 7). Similarly low mass balance figures for other reactions prompted us to investigate further. The $\mathrm{H} \beta$-catalysed reaction mixture was therefore worked up and purified by kugelröhr distillation to remove the unreacted starting material. The crude distillation residue was purified by flash column chromatography to give three isolated by-products, identified as compounds 6-8.
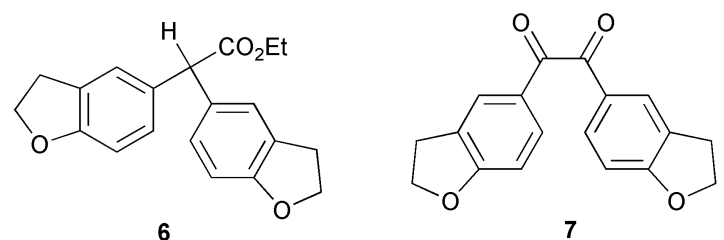

The structures of compounds $\mathbf{6}-\mathbf{8}$ were confirmed by NMR and mass spectra. The structure of compound 7 was further confirmed by synthesis. Reaction of two mole equivalents of $\mathbf{3}$ with one mole equivalent of oxalyl chloride in dichloromethane at room temperature and in the presence of $\mathrm{AlCl}_{3}$ as a catalyst afforded compound 7. Data obtained from the NMR and mass 
Table 8 Attempts to prevent the formation of the by-products $6-8^{a}$

\begin{tabular}{llll} 
& \multicolumn{2}{l}{${\text { Yield }(\%)^{b}}$} \\
\cline { 2 - 3 }$t / \mathrm{h}$ & $\mathbf{3}$ & $\mathbf{5}$ & Total mass $(\%)^{c}$ \\
\hline 72 & 42 & 34 & $76^{d}$ \\
72 & 60 & 16 & $76^{e}$ \\
72 & 53 & 26 & $79^{f}$ \\
168 & 63 & 33 & $96^{g}$ \\
168 & 56 & 42 & $98^{h}$ \\
168 & 25 & 73 & $98^{i}$
\end{tabular}

${ }^{a}$ A mixture of freshly calcined $\mathrm{H} \beta$ (2.00 g), ethyl oxalyl chloride $(2.73 \mathrm{~g}$, $20.0 \mathrm{mmol}), \mathrm{DHBF}(1.20 \mathrm{~g}, 10.0 \mathrm{mmol}), \mathrm{CH}_{2} \mathrm{Cl}_{2}(20.0 \mathrm{ml})$ and hexadecane $(0.70 \mathrm{~g}$, GC standard) was stirred under reflux for the stated reaction time. ${ }^{b}$ Determined by quantitative GC analysis. ${ }^{c}$ The sum of the calculated percentages of $\mathbf{3}$ and $\mathbf{5}$; a low mass figure indicates that a large quantity of the by-products 6-8 was present. ${ }^{d} \mathrm{DHBF}$ added at the start. ${ }^{e} \mathrm{DHBF}$ added dropwise over a period of $24 \mathrm{~h} .{ }^{f} \mathrm{DHBF}$ added at the start, but reaction carried out under nitrogen. ${ }^{g} \mathrm{DHBF}$ added over a period of $96 \mathrm{~h} .{ }^{h} \mathrm{DHBF}$ added over a period of $96 \mathrm{~h}$ under reflux conditions using ethyl oxalyl chloride $(20.0 \mathrm{ml})$ as a solvent. ${ }^{i} \mathrm{DHBF}$ added over a period of $96 \mathrm{~h}$ under reflux conditions over H $\beta(5.00 \mathrm{~g})$ using ethyl oxalyl chloride $(30.0 \mathrm{ml})$ as a solvent.
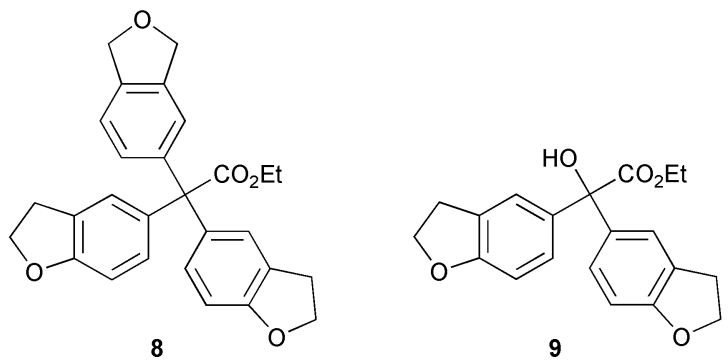

spectra of the isolated product matched the data for that isolated as a by-product from the $\mathrm{H} \beta$-catalysed reaction mixture. The formation of compound $\mathbf{6}$ appeared to involve attack of a further molecule of DHBF (3) on the ketone carbonyl group of 5 to give compound $\mathbf{9}$, followed by reduction. However, the mechanism of the reduction step remains unknown. Intermediate 9 could also be the precursor for compound 8. It is also conceivable that compound $\mathbf{9}$ could be formed via a benzilic acid type rearrangement from compound 7 , followed by transesterification.

Since the processes involved in formation of the by-products 6-8 involve reaction of 5 with excess DHBF, the key to preventing formation of such by-products would be to avoid having excess DHBF present in the reaction vessel. In an attempt to eliminate the formation of the by-products, therefore, a variety of different experimental procedures was investigated. The results obtained are shown in Table 8 .

It is clear from Table 8 that addition of DHBF over a longer period of time leads to a significant improvement in the total amount of compounds $\mathbf{3}$ and $\mathbf{5}$ that can be accounted for. The improvement in mass balance was observed because an excess of DHBF was avoided, thus reducing the chance of further reaction between it and the product 5. Further improvement in mass balance was achieved when ethyl oxalyl chloride was used in excess and as the solvent. Finally, a further improvement in yield was achieved by use of a larger amount of catalyst. Thus, when the reaction was carried out for $168 \mathrm{~h}$ under reflux conditions in ethyl oxalyl chloride $(30 \mathrm{ml})$ as solvent and over $\mathrm{H} \beta$ $(5.0 \mathrm{~g})$ as catalyst, the desired product 5 was formed in $73 \%$ yield and no other product was seen, the remaining mass balance being made up by unreacted DHBF.

\section{Conclusion}

The acylation of 2,3-dihydrobenzofuran (DHBF) with simple anhydrides over zeolite $\mathrm{H} \beta$ occurred readily over short reaction times under relatively mild conditions, giving the corresponding aromatic ketones regioselectively in good yields. In addition, yields of products obtained from reaction between DHBF and bulkier acylating agents such as trimethylacetic and benzoic anhydrides were improved upon by employing large pore zeolites and clays for longer reaction times. The procedure was also applied in the synthesis of ethyl (2,3-dihydrobenzofuran5 -yl)glyoxylate. Under conditions similar to those described above, the yield of acylation product was low. The yield could be improved under forcing conditions, but by-products involving further reaction with DHBF then began to accumulate. A high yield of the desired product could be obtained by conducting the reaction in ethyl oxalyl chloride as solvent at a high temperature for a prolonged period in the presence of a large quantity of catalyst. Consequently, there is still room for improvement in the clean and selective synthesis of that compound.

The solid catalyst can be recovered and reused with the avoidance of the toxic waste generated by traditional Lewis acid catalysts, which may help to make the process environmentally and commercially attractive.

\section{Experimental}

Commercially available starting materials (Aldrich) were used as supplied. Acid anhydrides (Aldrich, 99\%) were refluxed overnight over $\mathrm{P}_{2} \mathrm{O}_{5}$ and distilled under dry $\mathrm{N}_{2}$. Commercial zeolites were purchased from Aldrich Chemical Company or provided as a gift by Zeolyst International (formerly PQ zeolites). All solids were freshly calcined prior to the reaction by heating in air at $400{ }^{\circ} \mathrm{C}$ for a minimum of $6 \mathrm{~h}$ and cooled to room temperature in a desiccator over silica gel. GC was carried out using a PU 4400 Gas Chromatograph (Philips) fitted with a RTX-1 fused silica capillary column ( $30 \mathrm{~m} \times 0.32 \mathrm{~mm}$ ID) with dimethylpolysiloxane bonded phase. Hexadecane was added as an internal standard to allow quantification. ${ }^{1} \mathrm{H}$ and ${ }^{13} \mathrm{C}$ NMR spectra were recorded on a Bruker spectrometer operating at $400 \mathrm{MHz}$ for ${ }^{1} \mathrm{H}$ and $100 \mathrm{MHz}$ for ${ }^{13} \mathrm{C}$ measurement. Chemical shifts are reported in parts per million relative to tetramethylsilane. Low-resolution mass spectra were recorded on a VG 12 253 spectrometer, electron impact (EI) at $70 \mathrm{eV}$ and chemical ionization (CI) by use of ammonia as ionizing gas. Elemental analyses were obtained from the laboratories of the University of Wales, Cardiff.

\section{Typical reaction procedure}

Quantities are recorded in the footnotes of the appropriate tables. All reactions were carried out in a $25 \mathrm{ml}$ round bottomed flask fitted with a magnetic stirrer. Freshly calcined solid catalyst, acylating agent and aromatic substrate were added. The mixture was stirred at the appropriate temperature for the appropriate reaction time in the presence or absence of solvent. At the end of the reaction, the reaction mixture was diluted with ether or $\mathrm{CH}_{2} \mathrm{Cl}_{2}$, then filtered under vacuum. The filtrate was washed with distilled water $(2 \times 25 \mathrm{ml})$ and saturated $\mathrm{NaHCO}_{3}$ solution $(2 \times 25 \mathrm{ml})$. The organic layer was dried $\left(\mathrm{MgSO}_{4}\right)$, filtered and the solvent evaporated under reduced pressure. Quantitative analysis was achieved for the product mixture by GC. The product was purified by column chromatography if necessary. Further purification was achieved by recrystallisation when necessary. Confirmation of the product was achieved by use of NMR and mass spectral data.

1-(4-Methoxyphenyl)-2-phenylbutan-1-one 2. Oil, $\delta_{\mathrm{H}}\left(\mathrm{CDCl}_{3}\right)$ $8.00(\mathrm{~d}, J 8.8,2 \mathrm{H}), 7.25(\mathrm{~m}, 5 \mathrm{H}), 6.87(\mathrm{~d}, J 8.8,2 \mathrm{H}), 4.44(\mathrm{t}$, $J 7.3,1 \mathrm{H}), 3.78(\mathrm{~s}, 3 \mathrm{H}), 2.19(\mathrm{~m}, 1 \mathrm{H}), 1.87(\mathrm{~m}, 1 \mathrm{H})$ and $0.93(\mathrm{t}$, $J$ 7.3, $3 \mathrm{H}) ; \delta_{\mathrm{C}}\left(\mathrm{CDCl}_{3}\right) 198.6(\mathrm{~s}), 163.2(\mathrm{~s}), 140.1(\mathrm{~s}), 130.9$ (d), 130.0 (s), 128.8 (d), 128.2 (d), 126.7 (d), 113.7 (d), 55.4 (d), 55.1 (q), 27.1 (t) and 12.3 (q); $m / z$ (EI) $254\left(\mathrm{M}^{+}, 4 \%\right), 135$ (100), 
107 (10), 91 (39), 77 (23) and $51(5) ; \mathrm{m} / z(\mathrm{CI}) 272\left(\mathrm{M}^{+}+\mathrm{NH}_{4}\right.$, $8 \%), 255\left(\mathrm{MH}^{+}, 100\right)$ and $135(35)$.

1-(2,3-Dihydrobenzofuran-5-yl)propan-1-one 4a. Mp 58-59 ${ }^{\circ} \mathrm{C}, \delta_{\mathrm{H}}\left(\mathrm{CDCl}_{3}\right) 7.87(\mathrm{~d}, J 1.9,1 \mathrm{H}), 7.82(\mathrm{dd}, J 1.9,8.4,1 \mathrm{H}), 6.81$ $(\mathrm{d}, J 8.4,1 \mathrm{H}), 4.67(\mathrm{t}, J 8.8,2 \mathrm{H}), 3.26(\mathrm{t}, J 8.8,2 \mathrm{H}), 2.95(\mathrm{q}$, $J 7.3,2 \mathrm{H})$ and $1.22(\mathrm{t}, J 7.3,3 \mathrm{H}) ; \delta_{\mathrm{C}}\left(\mathrm{CDCl}_{3}\right) 199.4(\mathrm{~s}), 164.1$ (s), 130.4 (s), 129.8 (d), 127.6 (s), 125.3 (d), 108.9 (d), 72.1 (t), $31.4(\mathrm{t}), 29.0(\mathrm{t})$ and $8.6(\mathrm{q}) ; \mathrm{m} / \mathrm{z}(\mathrm{EI}) 176\left(\mathrm{M}^{+}, 16 \%\right), 147(100)$, 119 (21), 91 (82), 77 (13), 65 (85) and 51 (28); m/z (CI) 194 $\left(\mathrm{M}^{+}+\mathrm{NH}_{4}, 8 \%\right)$ and $177\left(\mathrm{MH}^{+}, 100\right)$.

1-(2,3-Dihydrobenzofuran-5-yl)-2-methylpropan-1-one $\mathbf{4 b}$. Oil, $\delta_{\mathrm{H}}\left(\mathrm{CDCl}_{3}\right) 7.86(\mathrm{~d}, J 1.9,1 \mathrm{H}), 7.81(\mathrm{dd}, J 1.9,8.4,1 \mathrm{H})$, $6.81(\mathrm{~d}, J 8.4,1 \mathrm{H}), 4.65(\mathrm{t}, J 8.7,2 \mathrm{H}), 3.50$ (septet, $J 6.8,1 \mathrm{H}$ ), $3.25(\mathrm{t}, J 8.7,2 \mathrm{H})$ and $1.20(\mathrm{t}, J 6.8,6 \mathrm{H}) ; \delta_{\mathrm{C}}\left(\mathrm{CDCl}_{3}\right) 203.0(\mathrm{~s})$, 164.1 (s), 130.1 (d), 129.5 (s), 127.7 (s), 125.6 (d), 109.0 (d), 72.1 (t), 34.9 (d), 29.1 (t) and $19.4(\mathrm{q}) ; \mathrm{m} / z$ (EI) $190\left(\mathrm{M}^{+}, 12 \%\right), 147$ (100), 119 (21), 91 (86), 77 (13), 65 (92) and 51 (24); $\mathrm{m} / \mathrm{z}$ (CI) 208 $\left(\mathrm{M}^{+}+\mathrm{NH}_{4}, 10 \%\right), 191\left(\mathrm{MH}^{+}, 100\right)$ and $147(20)$.

1-(2,3-Dihydrobenzofuran-5-yl)-2,2-dimethylpropan-1-one 4c. Oil, $\delta_{\mathrm{H}}\left(\mathrm{CDCl}_{3}\right) 7.73(\mathrm{~m}, 2 \mathrm{H}), 6.77(\mathrm{~d}, J 8.3,1 \mathrm{H}), 4.64(\mathrm{t}, J 8.8$, $2 \mathrm{H}), 3.25(\mathrm{t}, J 8.8,2 \mathrm{H})$ and $1.38(\mathrm{~s}, 9 \mathrm{H}) ; \delta_{\mathrm{C}}\left(\mathrm{CDCl}_{3}\right) 206.3(\mathrm{~s})$, 162.8 (s), 130.3 (s), 130.2 (d), 127.0 (s), 126.2 (d), 108.4 (d), 71.9 (t), 43.8 (s), 29.2 (t) and 28.5 (q); $\mathrm{m} / \mathrm{z}(\mathrm{EI}) 204\left(\mathrm{M}^{+}, 5 \%\right), 147$ (100), 119 (12), 91 (28), 77 (3), 65 (18) and 51 (12); m/z (CI) 222 $\left(\mathrm{M}^{+}+\mathrm{NH}_{4}, 3 \%\right), 205\left(\mathrm{MH}^{+}, 100\right)$ and $147(15)$.

1-(2,3-Dihydrobenzofuran-5-yl)phenylmethanone 4d. Oil, $\delta_{\mathrm{H}}\left(\mathrm{CDCl}_{3}\right) 7.74(\mathrm{~m}, 3 \mathrm{H}), 7.65(\mathrm{dd}, J 1.8,8.4,1 \mathrm{H}), 7.55(\mathrm{~d}$, $J 1.8,1 \mathrm{H}), 7.46(\mathrm{t}, J 7.5,2 \mathrm{H}), 6.82(\mathrm{~d}, J 8.4,1 \mathrm{H}), 4.67(\mathrm{t}, J 8.8$, $2 \mathrm{H})$ and $3.26(\mathrm{t}, J 8.8,2 \mathrm{H}) ; \delta_{\mathrm{C}}\left(\mathrm{CDCl}_{3}\right) 195.6(\mathrm{~s}), 164.2(\mathrm{~s})$, 138.6 (s), 132.5 (d), 131.7 (d), 130.4 (s), 129.6 (d), 128.2 (d), $127.6(\mathrm{~s}), 127.5(\mathrm{~d}), 108.8(\mathrm{~d}), 72.2(\mathrm{t})$ and $29.0(\mathrm{t}) ; \mathrm{m} / \mathrm{z}(\mathrm{EI}) 224$ $\left(\mathrm{M}^{+}, 3 \%\right), 147(10), 119(3), 105(88), 77(100)$ and $51(50) ; \mathrm{m} / \mathrm{z}$ (CI) $242\left(\mathrm{M}^{+}+\mathrm{NH}_{4}, 2 \%\right), 225\left(\mathrm{MH}^{+}, 100\right)$ and $147(10)$.

2-Chloro-1-(2,3-dihydrobenzofuran-5-yl)ethanone 4e. Mp 73$74{ }^{\circ} \mathrm{C}, \delta_{\mathrm{H}}\left(\mathrm{CDCl}_{3}\right) 7.82(\mathrm{~m}, 2 \mathrm{H}), 6.83(\mathrm{~d}, J 8.4,1 \mathrm{H}), 4.68(\mathrm{t}$, $J$ 8.8, $2 \mathrm{H}), 4.64(\mathrm{~s}, 2 \mathrm{H})$ and $3.27(\mathrm{t}, J 8.8,2 \mathrm{H}) ; \delta_{\mathrm{C}}\left(\mathrm{CDCl}_{3}\right) 189.5$ (s), 165.2 (s), 130.7 (d), 128.2 (s), 127.4 (s), 126.0 (d), 109.4 (d), $72.4(\mathrm{t}), 45.8(\mathrm{t})$ and $20.3(\mathrm{t}) ; \mathrm{m} / \mathrm{z}(\mathrm{EI}) 198\left(\mathrm{M}^{+37} \mathrm{Cl}, 1 \%\right), 196$ $\left(\mathrm{M}^{+35} \mathrm{Cl}, 3\right), 147(100), 119$ (12), 91 (46), $86(20), 84$ (31), 77 (24), 65 (36) and $51(52) ; \mathrm{m} / \mathrm{z}(\mathrm{CI}) 216\left(\mathrm{M}^{+37} \mathrm{Cl}+\mathrm{NH}_{4}, 1 \%\right)$, $214\left(\mathrm{M}^{+35} \mathrm{Cl}+\mathrm{NH}_{4}, 3\right), 199\left(\mathrm{MH}^{+37} \mathrm{Cl}, 3\right), 197\left(\mathrm{MH}^{+35} \mathrm{Cl}, 9\right)$ and 147 (100) (Found: $\mathrm{C}, 60.8 ; \mathrm{H}, 4.8$. Calc. for $\mathrm{C}_{10} \mathrm{H}_{9} \mathrm{ClO}_{2}$ : C, $61.08 ; \mathrm{H}, 4.61 \%)$.

Ethyl (2,3-dihydrobenzofuran-5-yl)glyoxylate 5. Oil, $\delta_{\mathrm{H}}\left(\mathrm{CDCl}_{3}\right) 7.89(\mathrm{~d}, J 1.9,1 \mathrm{H}), 7.85(\mathrm{dd}, J 1.9,8.4,1 \mathrm{H}), 6.85(\mathrm{~d}$, $J 8.4,1 \mathrm{H}), 4.70(\mathrm{t}, J 8.8,2 \mathrm{H}), 4.43(\mathrm{q}, J 7.2,2 \mathrm{H}), 3.27(\mathrm{t}, J 8.8$, $2 \mathrm{H})$ and $1.42(\mathrm{t}, J 7.2,3 \mathrm{H}) ; \delta_{\mathrm{C}}\left(\mathrm{CDCl}_{3}\right) 184.9(\mathrm{~s}), 166.1(\mathrm{~s})$, 164.4 (s), 132.8 (d), 128.4 (s), 127.2 (d), 125.8 (s), 109.7 (d), 72.6 (t), $62.1(\mathrm{t}), 28.7(\mathrm{t})$ and $14.1(\mathrm{q}) ; \mathrm{m} / \mathrm{z}(\mathrm{EI}) 220\left(\mathrm{M}^{+}, 2 \%\right)$, 147 (100), 119 (12), 91 (22), 65 (16) and 49 (25); $\mathrm{m} / \mathrm{z}$ (CI) 238 $\left(\mathrm{M}^{+}+\mathrm{NH}_{4}, 18 \%\right), 221\left(\mathrm{MH}^{+}, 100\right)$ and $147(10)$.

Ethyl bis(2,3-dihydrobenzofuran-5-yl)ethanoate 6. Oil, $\delta_{\mathrm{H}}\left(\mathrm{CDCl}_{3}\right) 7.14(\mathrm{~d}, J 1.5,2 \mathrm{H}), 7.03(\mathrm{dd}, J 1.5,8.2,2 \mathrm{H}), 6.72(\mathrm{~d}$, $J 8.2,2 \mathrm{H}), 4.87(\mathrm{~s}, 1 \mathrm{H}), 4.54(\mathrm{t}, J 8.7,4 \mathrm{H}), 4.19(\mathrm{q}, J 7.1,2 \mathrm{H})$, $3.17(\mathrm{t}, J 8.7,4 \mathrm{H})$ and $1.25(\mathrm{t}, J 7.1,3 \mathrm{H}) ; \delta_{\mathrm{C}}\left(\mathrm{CDCl}_{3}\right) 173.3(\mathrm{~s})$, $159.2(\mathrm{~s}), 131.3(\mathrm{~s}), 128.2(\mathrm{~d}), 127.4(\mathrm{~s}), 125.0(\mathrm{~d}), 109.1(\mathrm{~d}), 71.3$ (t), $61.0(\mathrm{t}), 55.9(\mathrm{~d}), 29.7(\mathrm{t})$ and $14.2(\mathrm{q}) ; \mathrm{m} / \mathrm{z}(\mathrm{EI}) 324\left(\mathrm{M}^{+}\right.$, $5 \%), 251(100)$ and $147(47) ; m / z(C I) 342\left(\mathrm{M}^{+}+\mathrm{NH}_{4}, 15 \%\right)$, $325\left(\mathrm{MH}^{+}, 8\right), 251(35)$ and $205(100)$.

Bis(2,3-dihydrobenzofuran-5-yl)ethanedione 7. Oil, $\delta_{\mathrm{H}}\left(\mathrm{CDCl}_{3}\right)$ $7.70(\mathrm{~d}, J 1.3,2 \mathrm{H}), 7.60(\mathrm{dd}, J 1.3,8.3,2 \mathrm{H}), 6.81(\mathrm{~d}, J 8.3,2 \mathrm{H})$, $4.66(\mathrm{t}, J 8.7,4 \mathrm{H}), 3.26(\mathrm{t}, J 8.7,4 \mathrm{H}) ; \delta_{\mathrm{C}}\left(\mathrm{CDCl}_{3}\right) 194.7(\mathrm{~s})$ 163.7 (s), 131.9 (d), 131.2 (s), 127.3 (s), 127.2 (d), 108.6 (d), 72.1 (t) and $29.2(\mathrm{t}) ; \mathrm{m} / \mathrm{z}(\mathrm{EI}) 294\left(\mathrm{M}^{+}, 2 \%\right), 147$ (100), $119(20), 91$ (60), 65 (60) and 51 (12); $m / z$ (CI) $312\left(\mathrm{M}^{+}+\mathrm{NH}_{4}, 80 \%\right), 295$ $\left(\mathrm{MH}^{+}, 100\right)$ and $147(25)$

Ethyl tris(2,3-dihydrobenzofuran-5-yl)ethanoate 8. Oil, $\delta_{\mathrm{H}}\left(\mathrm{CDCl}_{3}\right) 7.00(\mathrm{~d}, J 1.2,3 \mathrm{H}), 6.88(\mathrm{dd}, J 1.2,8.5,3 \mathrm{H}), 6.67(\mathrm{~d}$, $J 8.5,3 \mathrm{H}), 4.56(\mathrm{t}, J 8.7,6 \mathrm{H}), 4.30(\mathrm{q}, J 7.1,2 \mathrm{H}), 3.15(\mathrm{t}, J 8.7$, $6 \mathrm{H})$ and $1.22(\mathrm{t}, J 7.1,3 \mathrm{H}) ; \delta_{\mathrm{C}}\left(\mathrm{CDCl}_{3}\right) 174.5(\mathrm{~s}), 158.7(\mathrm{~s})$, 136.0 (s), $130.2(\mathrm{~d}), 126.8$ (d), $126.2(\mathrm{~s}), 108.1(\mathrm{~d}), 71.4(\mathrm{t}), 66.1$ (s), $61.5(\mathrm{t}), 29.8(\mathrm{t})$ and $14.0(\mathrm{q}) ; \mathrm{m} / z(\mathrm{EI}) 442\left(\mathrm{M}^{+}, 2 \%\right)$ and 369 (100); $\mathrm{m} / z(\mathrm{CI}) 460\left(\mathrm{M}^{+}+\mathrm{NH}_{4}, 2 \%\right), 369(40)$ and $323(100)$.

\section{Acknowledgements}

We thank the University of Wales Swansea, Pfizer Central Research and the EPSRC for financial support, and the EPSRC Mass Spectrometry Centre at Swansea for mass spectra. We also thank the EPSRC, the Higher Education Funding Council for Wales (ELWa-HEFCW) and the University of Wales Swansea for grants that enabled the purchase and upgrading of NMR equipment used in the course of this work, and Zeolyst International for gifts of zeolites. G. A. El-Hiti thanks the Royal Society of Chemistry for an international author grant.

\section{References}

1 Friedel-Crafts Chemistry, ed. G. A. Olah, Wiley-Interscience, New York, 1973.

2 K. Smith and S. D. Roberts, Catal. Today, 2000, 60, 227; K. Smith, S. D. Roberts and G. A. El-Hiti, Org. Biomol. Chem., 2003, 1, 1552.

3 K. Smith and G. Pollaud, J. Chem. Soc., Perkin Trans. 1, 1994, 3519.

4 K. Smith and D. Bahzad, Chem. Commun., 1996, 467; K. Smith, G. A. El-Hiti, M. E. W. Hammond, D. Bahzad, Z. Li and C. Siquet, J. Chem. Soc., Perkin Trans. 1, 2000, 2745.

5 K. Smith, P. He and A. Taylor, Green Chem., 1999, 1, 35.

6 K. Smith, M. Butters and B. Nay, Synthesis, 1985, 1157.

7 K. Smith, M. Butters, W. E. Paget, D. Goubet, E. Fromentin and B. Nay, Green Chem., 1999, 1, 83

8 K. Smith, G. M. Ewart and K. R. Randles, J. Chem. Soc., Perkin Trans. 1, 1997, 1085.

9 K. Smith, K. Fry, M. Butters and B. Nay, Tetrahedron Lett., 1989, 30, 5333 .

10 K. Smith, A. Musson and G. A. DeBoss, J. Org. Chem., 1998, 63, 8448 .

11 K. Smith, T. Gibbins, R. W. Millar and R. P. Claridge, J. Chem. Soc., Perkin Trans. 1, 2000, 2753.

12 K. Smith, S. Almeer and S. J. Black, Chem. Commun., 2000, 1571.

13 K. Smith, S. Almeer and C. Peters, Chem. Commun., 2001, 2748.

14 K. Smith, S. Almeer, S. J. Black and C. Peters, J. Mater. Chem., 2002, 12, 3285 .

15 M. Butters, in Solid Supports and Catalysts in Organic Synthesis, ed. K. Smith, Ellis Horwood, Chichester, 1992, pp. 130-170.

16 J. H. Clark, S. R. Cullen, S. J. Barlow and T. W. Bastock, J. Chem. Soc., Perkin Trans. 2, 1994, 1117.

17 See for example: C. Gauthier, B. Chiche, A. Finiels and P. Geneste, J. Mol. Catal., 1989, 50, 219; D. E. Akporiaye, K. Daasvatn, J. Solberg and M. Stöcker, Stud. Surf. Sci. Catal., 1993, 78, 521; I. Neves, F. Jayat, P. Magnoux, G. Pérot, F. R. Ribeiro, M. Gubelmann and M. Guisnet, J. Mol. Catal., 1994, 93, 169; K. Gaare and D. E. Akporiaye, J. Mol. Catal., 1996, 109, 177; J. M. Escola and M. E. Davis, Appl. Catal., A, 2001, 214, 111; A. E. W. Beers, T. A. Nijhuis, F. Kapteijn and J. A. Moulijn, Micropor. Mesopor. Mater, 2001, 48, 279; C. Castro, A. Corma and J. Primo, J. Mol. Catal. A: Chem., 2002, 177, 273; C. P. Bezouhanova, Appl. Catal. A, 2002, 229, 127.

18 M. Spagnol, L. Gilbert, R. Jacquot, H. Guillot, P. J. Tirel and A.-M. Le Govic, Abstract P1, pp. 91-92, in the Book of Abstracts of the Fourth International Symposium on Heterogeneous Catalysis and Fine Chemicals, Basel, Switzerland, September 8-12, 1996; M. Spagnol, E. Benazzi and C. Marcilly, US Patent 1998, 5,817,878.

19 K. Smith, Z. Zhenhua and P. K. G. Hodgson, J. Mol. Catal. A: Chem., 1998, 134, 121; K. Smith, Z. Zhenhua, L. Delaude and P. K. G. Hodgson, Abstract O18, pp. 62-63, in the Book of Abstracts of the Fourth International Symposium on Heterogeneous Catalysis and Fine Chemicals, Basel, Switzerland, September 8-12, 1996.

20 K. Smith, G. A. El-Hiti, A. J. Jayne and M. Butters, Org. Biomol. Chem., 2003, 1, 1560 